\title{
The Effects of Altruism and Social Background in an Online-Based, Pay-What-You-Want Situation
}

\author{
Hanna Peschla, Augustin Suessmair, Gerd Meier \\ Leuphana University of Lueneburg, Lueneburg, Germany \\ Email:hanna.peschla@stud.leuphana.de,suessmair@uni.leuphana.de,meier@leuphana.de
}

How to cite this paper: Peschla, H., Suessmair, A. and Meier, G. (2017) The Effects of Altruism and Social Background in an Online-Based, Pay-What-You-Want Situation. American Journal of Industrial and Business Management, 7, 245-269. https://doi.org/10.4236/ajibm.2017.73018

Received: January 27, 2017

Accepted: March 28, 2017

Published: March 31, 2017

Copyright $\odot 2017$ by authors and Scientific Research Publishing Inc. This work is licensed under the Creative Commons Attribution-NonCommercial International License (CC BY-NC 4.0).

http://creativecommons.org/licenses/by-nc/4.0/

(c) (7) (8) Open Access

\begin{abstract}
Pay-What-You-Want (PWYW) is a participative pricing mechanism that leaves it up to the customer to choose a purchase price. Presently, the factors that influence customers' willingness to pay are still not completely understood. This study examines the degree to which willingness to pay in an anonymous PWYW purchase situation on the Internet is influenced by the social motif of altruism and communication that as a part of the purchase price, will be donated to a charitable institution identified in advance. We hypothesized that altruism as well as a social background exerted an increasing impact on willingness to pay. A specific purchase situation in which the social background was manipulated was simulated by using online surveys. Altruism was measured using a 7-point Likert-type scale. The sample consisted of 403 participants, predominantly students and young adult employees. We found that communication of a social background led to a highly significant increase in willingness to pay $(p<0.001)$. Furthermore, altruism positively impacted the willingness to pay only on the condition that a social background was communicated $(p<0.001)$. The insights acquired provide evidence for multiple theoretical assumptions that postulate a relation between willingness to pay and the social background of a purchase situation. The interaction effect of altruism and social background explains why researchers have rarely succeeded in showing a fundamental effect of altruism on the willingness to pay in anonymous PWYW situations: To stimulate this correlation, additional characteristics of the purchase scenario seem to be determinative.
\end{abstract}

\section{Keywords}

Pay-What-You-Want, Altruism, Social Background, Charity, Willingness-to-Pay, Participative Pricing 


\section{Introduction}

The price of a product or a service plays an important role for the supplier as well as for the demander. Among the three profit drivers (i.e., price, sales volume and costs), price is the most effective, so that it becomes a marketing instrument for the seller. Nowadays, psychological effects play a role in decisions surrounding pricing mechanisms and the evaluation of a perceived price, which sometimes seems to be inconsistent with the economic rationality. This is where the Pay-What-You-Want (PWYW) pricing mechanism applies [1]. As part of the group of participative pricing mechanisms, PWYW is characterized by the fact that the buyer of a product or service actively participates in the pricing, so that this is not only determined by the seller's side. It follows that these pricing models can be clearly distinguished from the fixed price model. Fixed prices mean that the seller determines a price and does not allow the buyer to be a part of the price discovery process. Among participative pricing mechanisms, PWYW is an extreme version because it gives the buyer the full control in choosing a price. Dependent on the buyer's individual willingness to pay (WTP), PWYW transactions allow buyers to pay exactly as much as they desire. The seller must accept the buyer's price and cannot withdraw from the offer. Individual and dynamic prices become possible, which results in access to different customer segments. However, a payment of zero also can easily be made [2]. Because of its innovative character and attention-grabbing concept, PWYW enjoys increasing attention from researchers conducting empirical studies and exploring practical applications. As there is still a lack of research, the present research examines for which areas PWYW is suitable and profitable and which internal and external factors influence customers' WTP. PWYW is mainly used for goods and services with relatively low variable costs and high fixed costs that are action-based and therefore, limited in time or space [3]. In 2007, the English rock band Radiohead came up with a positive practical example when they released their new album "In Rainbows": Via Internet and for a period of two months, customers were able to download it for a price of their choice. Afterwards, the band reported that the PWYW pricing mechanism proved profitable [4] and caused an increase in their fan base that paid off with an increased number of buyers for their next album [5]. Ju-Young Kim, Martin Natter and Martin Spann directed the first scientific knowledge and laid the foundation stone for many studies that followed with their investigation of PWYW in three field studies. They did not just determine that customers do pay more than zero under PWYW conditions but also discovered factors that influence WTP [4]. Subsequent research confirmed Kim et al.'s results or provided complementary or contradictory findings. For example, Kim et al. inferred that altruism only impacts the WTP in PWYW situations in which there is a large degree of personal closeness between buyer and seller [4], and subsequent studies provided evidence for an significant effect of altruism when PWYW is used on the Internet with anonymity instead of personal closeness [6] [7]. The rapid growth of the Internet emphasizes the importance of these findings because it allows easier interactions between seller and 
buyer, which facilitates the use of innovative pricing mechanisms. By 2008, a quarter of the total sales volume on the Internet was sold under PWYW conditions [8]. The expected increasing use of PWYW makes it all the more important to provide evidence about its effectiveness and feasibility.

\section{Literature Review}

Chandran and Morwitz showed that participative pricing mechanisms lead to an increased purchase intention compared to the fixed price model [9]. In addition to Radiohead mentioned above, also other sellers in the offline world concluded that the idea that buyers always think in an economically rational way, which suggests prices of zero under PWYW conditions cannot be transferred to the real world. In 2005, a restaurant, "Wiener Deewan", opened in Vienna with the concept that people pay fixed prices for their drinks but can freely choose whether and how much they pay for their food [4]. Presently, the restaurant runs successfully and the operators have stated that all customers pay as much for their food as it is worth to them, which usually depends on their financial status. All in all, consumers make a fair contribution [10]. In addition to gastronomy, further applications of PWYW are predominantly found in museums, zoos and the hotel industry [11]. The spread of PWYW also increased on the Internet: Music platforms, musicians and comedians followed the example of Radiohead and even the dating platform "AdamEven.de" gave it a try. In contrast to the operators of the Wiener Deewan, most suppliers opt for a time-limited use of PWYW. In this view, the aims of new customer acquisition and increased buying intensity supersede the goals of buyers who in the long run pay on average more than the regular fixed prices [12]. That PWYW is mainly applied to goods and services with relatively low variable and high fixed costs can be explained by the associated lower risk compared to products with relatively high variable costs.

After conducting three PWYW-related field studies in the service sector, Kim et al. [4] validated this approach for online as well as the offline world. They determined that the prices paid are significantly greater than zero and that WTP is influenced by customers' internal reference prices. Fairness, satisfaction, price consciousness and income impact how much the buyers are willing to give of their internal reference price to the seller; in other words, how much profit sellers derive from the PWYW deal. In contrast to these factors, altruism and loyalty only influenced WTP in one of the three studies [4]. For the restaurant Wiener Deewan, a two-year, long-term study proved that customers' WTP is significantly greater than zero [13]. The researchers explained that one's paying for a received service corresponds to a social norm. Buyers face a trade-off between following the social norm and maximizing economic benefits. The emotional costs of deviation from the norm seem to outweigh the payment of a price that is universally viewed as fair. Other researchers have confirmed that buyers want to avoid sanction costs that might be associated with their disregarding social norms and showed that sometimes, people favor fixed prices over PWYW because they just do not want the face this trade-off [14]. 
Later studies focused on the analysis of PWYW in different situations, distribution channels, for different goods and services and on which individual characteristics have impact on WTP. Kunter [7] confirmed the influence of fairness, satisfaction and income. Moreover, he affirmed that another significant driver is the avoidance of feelings of guilt. This was also shown by Regner, whose study concentrated on the case of online music [11]. The influence of prosociality also led to the finding that one motivator for payments above zero in anonymous PWYW situations is the willingness to let the seller remain on the market [15]. Other empirical studies found that WTP is also greater than zero in PWYW situations that apply no social pressure and in which the buyer is anonymous [16] and that PWYW works especially well with customers who like to behave in ways that are compliant with social norms [17]. In Hilbert and Suessmair's study [18], the impact of social norm compliance on WTP was just slightly not significant. Nevertheless, PWYW seems to be applicable in public as well as anonymous situations, but the social distance between buyer and seller or additional fellow human beings on the one hand, and the extent of social interaction on the other hand, have a considerable impact on WTP. A laboratory experiment resulted in significant differences in WTP between participants without any social interaction while choosing a price with participants interacting with the experimenter or an additional, third person [18]. Another hypothetical online experiment showed the positive influence of increased social interaction on the WTP, although on this occasion, whether the buyer only interacted with the seller or was additionally observed by another person made a difference [19]. Lee, Baumgartner and Pieters [20] found that the identity of a third person plays a role, as did the extent to which the buyer wishes to make a good impression on that person. Evidence for the existence of a positive impact of reduced anonymity on WTP in the online world was found in a study in which the artist could see every customer's name and chosen price in an online music store that used PWYW led to a higher WTP [21].

The long-term study of the restaurant Wiener Deewan identified another influential factor: With the mood as mediator, weather affects WTP [13].

Because there was evidence that buyers orient themselves according to their internal reference price [4] [17], the examination of an effect caused by the provision of an external reference price came to the fore. Similar studies all consistently concluded that buyers are influenced by external reference prices in any case [7] [11] [16] [22] [23] [24] [25] [26]. Sellers should provide information about a reference price if they assume that this external reference price is higher than the customer's internal reference prices and that the buyers would evaluate the external reference price as reasonable. According to current research, it is difficult for people to assess realistic prices, so that without an external reference price, there is a high risk that buyers orient on completely wrong, mostly too low, price expectations or heuristics. After Kim et al. [4] identified altruism as an influential factor on WTP in the one their three studies that dealt with the sale of hot beverages in a delicatessen in Wiesbaden (Germany), they concluded that 
altruism is only relevant when there is a high degree of personal closeness between buyer and seller. Altruism presents a motif for social actions that aim to be useful for other people. However, it is possible that individuals who are motivated by altruism also increase their own well-being in doing so. This impure form of altruism, sometimes called a warm glow, often confers a pleasant, warm feeling for the doer [27].

In 2010, Regner showed a weak positive impact of altruism on WTP in an anonymous PWYW scenario and interpreted it as a case of warm glow [7]. However, the items he used to measure altruism were extremely tailored to the specific case of buying online music. In addition, the factors generosity and reciprocity, which are related to altruism, were effective drivers under PWYW conditions [28]. In parallel, people who are prosocial exhibit a higher WTP than those who are pro-self [29]. The online study of Dorn and Suessmair [19] found that altruism is more important for WTP in PWYW situations that include lot of social interaction than in anonymous PWYW situations. Therefore, the authors expended the conclusion of Kim et al. [4] by the finding that altruism does not affect WTP only in situations that involve a high degree of personal closeness between buyer and seller but that altruism has a stronger influence than in anonymous situations. Next, Schmidt et al. [15] attributed positive WTP in an anonymous PWYW scenario inter alia to altruistic action motivation. Furthermore, another questionnaire-based survey proved this influence by identifying the internal reference price as a mediator variable [17]. The extent to which altruism is relevant when buyers have access to external reference prices is as yet unknown.

Finally, recent research showed a positive correlation between altruism and WTP in an online-based PWYW purchase scenario [6]. The effect was independent of whether or not there was an external reference price provided, whether or not there was anonymity and whether or not the situation involved the purchase of a digital or non digital product with relatively high variable costs attributed to its physical makeup. There is a great need to replicate this result so that there is more clarity about how decisively particular, individual characteristics of a PWYW situation impact altruism in WTP. It is also necessary to provide evidence for the assumption that the existence of a social background in a PWYW situation has a positive influence on the pricing process. A field study that dealt with the purchase of souvenir photos in a leisure park indicated that communicating the information that half of the freely chosen price would be donated to a specific, nationally known charity led to an increase in demand and WTP compared to so-called normal, pure PWYW [30]. Moreover, an online questionnairebased survey concluded that the entire profit's being donated results in a higher WTP [29]. Other research has recommended a combination of PWYW and a charity [6] [17] [28]. All in all, in addition to scarce empirical evidence, there are many hypotheses concerning the positive impact of social background on WTP in PWYW situations. It also remains open whether the previous findings can be transferred to anonymous scenarios like those on the Internet. In sum, the amount of research on PWYW increased greatly within the last years, classifying 
this pricing mechanism as definitely noteworthy. However, the investigations of the PWYW phenomenon are not yet completed because of the partly contradictory and partly incomplete outcomes. This study seeks to shed some light on the influence of altruism and social background in a PWYW situation with specific characteristics because there is still a lack of evidence concerning this. The little previous research did not deal with or solely found no or just minor positive effects of these two factors on WTP when PWYW is applied on the Internet, especially by providing an external reference price. Therefore, the present study achieves a significant contribution to reduce the current research gap. An experiment using online questionnaires was conducted. Participants were buyers who wanted to order a non digital guidebook under PWYW conditions on the Internet. Information about the alleged normal fixed price was given, oriented on the German average price for guidebooks in 2015. To determine the influence of altruism on the WTP, altruism was measured using a 7-point Likert-type scale. In addition, the social background was manipulated by adding a charity background to the PWYW situation for half of the participants. According to current research and theories, we hypothesized that the extent of the social motif altruism and the communication of a social background has a positive impact on WTP. Ultimately, this innovative research should enrich the exploration of PWY$\mathrm{W}$ and also contribute to practice by advising sellers on the decision whether and how to apply PWYW.

\section{Method}

\subsection{Participants}

Because the study involved an online survey, it was possible to recruit a convenience sample via the Internet, using emails, Leuphana University Lueneburg internal newsletters, and social networks such as XING, LinkedIn and Facebook. The participants used a link to access the survey. We evaluated data from 403 participants ( $\mathrm{n}=305$ female and 98 male). The sample consisted mainly of young adults: more than $70 \%$ of the participants were between 19 and 25 years old and a further $16.4 \%$ were between 26 and 35 years old $\left(M_{\text {age }}=25.03\right.$ years, $S D_{\text {age }}=$ 9.64 years, range: 14 - 77 years). In accordance with this age distribution, about $90 \%$ possessed as highest educational achievement a degree of higher education entrance qualifications or a university degree. These characteristics are reflected in the distribution of professional activity and monthly net income: About two-thirds of the participants were university students with a monthly net income less than 1000 euros. Moreover, $15.9 \%$ were employees and $18.4 \%$ reported a monthly net income of 1000 to 2000 euros. The questionnaires were written in German; only a few participants were not German citizens but had a command of the German language. Only 5\% of the sample stated that they would never take advantage of the opportunity of online-purchase and about two-thirds reported they shopped on the Internet daily, weekly or at least several times per month. It is therefore reasonable to assume that the majority of participants were familiar with the scenario of buying products online. This reinforces the transferability of the 
results to reality. Students of Leuphana University Lueneburg received a certificate for their participation in the survey, which is mandatory for business psychology and psychology students. There was no other remuneration to avoid people's participating only to receive the certificate who might not behave conscientiously and seriously when completing the questionnaire.

\subsection{Design and Measures}

To explore how buyers' personal degree of altruism and social background of PWYW situations influence customers' WTP, the freely chosen price of the participants represented the dependent variable willingness to pay. As this was the only dependent variable, this is a univariate experiment [31]. WTP was measured by an open question that asked for a value in euros and cents to avoid participants' stating threshold prices (e.g., "10 euros") and to instead obtain price quotes that would be as accurate as possible. We used a two-factor study design, with social background as one independent variable with two factor levels. Each participant received one of two possible PWYW scenarios such that the sample was divided into two groups with a randomized allocation. The communication of the social background differed for the two groups such that only one group received the information that half of their purchase price would be donated to a specific charity. It follows that the members of the other group would assume that their whole payment would benefit the seller. Compared to a within-subjects design, this between-subjects design has the advantage that no position- or carry-over effects are possible [31]. The participant's degree of altruism was measured by an established 7-point scale from the International Personality Item Pool [32], with the labeled end points, "entirely disagree" and "entirely agree". The scale consists of five equally weighted items so that it was possible to calculate an average value for every participant that lies between 1 (least possible degree of altruism) and 7 (highest possible degree of altruism). In summary, altruism and WTP were handled as metric, interval-scaled variables and social background was a dichotomous categorical variable.

\subsection{Characteristics of the Simulated Purchase Situation}

To design the PWYW scenario, it was necessary to decide on the purchased product, on a charitable organization for the group with communication of a social background and the provision of an external reference price. The main goal was to develop a purchase situation that seemed realistic to the participants in their role as customer. For the purpose of gaining usable data, the selection of concrete contents ensured that all of the participants acted on the basis of the same foundations and not on unanswered questions. Thereby, we controlled to allow no considerable impact of completely different, potentially false ideas about realistic average prices or personal attitudes toward certain authors or charitable organizations in general on the WTP.

A non digital guidebook was chosen as the product that customers would order online and that would be sent to them afterward. Because of the steadily 
growing importance of the Internet and related electronic commerce (i.e., e-commerce), this represents an appealing leverage point for participative pricing mechanisms. Books are one of the three bestselling goods on the Internet [33] [34] [35], so one can conclude that people are relatively familiar with ordering books online. Compared to other book types, guidebooks serve more to inform than to entertain, which is why one can assume that people associate relatively little emotion with them. Both this and the waiver of a specific book title negated the influence of customer's personal attitudes toward certain books on WTP. Furthermore, guidebooks usually come up with a lower price than books in general. This strengthens the information value of an average price. A representative statistic indicates that this amount was 14.47 euros in Germany in 2015, which was given as the regular fixed price of the guidebook to the participants [36]. With the provision of an external reference price, legal advantages arise: In terms of the German Price Indication Ordinance (Preisangabenverordnung), price labeling is always necessary to comply with the principle that prices reflect costs. Under PWYW conditions, this criterion is sufficiently met by providing a reference price [12]. To design a scenario as realistically as possible, a specific, existing and regionally located recipient of the donation was selected: The research institute of the Kinderkrebs-Zentrum Hamburg gGmbH. Research has shown that people tend to donate if any and to donate more when the recipient is clearly defined and also known [37]. This way, it becomes possible to build an emotional connection to the recipient's concern [28].

\subsection{Procedure}

The questionnaires used for the study were created using the Web-based software EvaSys. Afterward, the data were imported into the statistical program SPSS for evaluation. To access the online questionnaire, everything the participants needed was provided by a link and an Internet connection. Because of variation of the independent variable social background, two questionnaires were created. They were absolutely identical apart from the differences in the two factor levels of this variable. To ensure randomized allocation, a link was programmed that alternately led to the one or the other questionnaire with each activation. As the participants did not know about the purpose of the study and the existence of two slightly different questionnaires, bias of results due to this were prevented. Thus, invalid data because of participants' knowledge about being part of the group that receives (no) information about a social background unlike the other group was avoided. Use of online questionnaires guaranteed a standardized test procedure and no experimenter expectancy effects could occur [31]. Access to the survey was possible from July 25, 2016 to August 8, 2016. To motivate as many people as possible to participate and to avoid effects of fatigue and problems of understanding, the questionnaires were kept as short and precise as possible and incomprehensible specialized terms were avoided. Before starting the official research study, a pretest with 20 participants was conducted to detect and take action on difficulties with data input and evaluation. Feedback on visual design was also obtained 
because a well-conceived layout guarantees a better orientation and thus more valid data. Thanks to the pretest, the processing time was estimated at 5 to $10 \mathrm{mi}$ nutes maximum. The questionnaires started with a short introduction that described the study, called on the participant's consciousness and removed any possible fear that might have been associated with evaluation of the participant's decision. In addition, there was information about data protection and contact details. On the next page, the purchase situation with its characteristics and the PWYW pricing mechanism were explained. The participant was asked assume the role of a customer who could freely chose a price and that the seller would accept any offer. Furthermore, we provided information about the anonymity of the situation by noting that customers' names and purchase prices would not be published. We did not specifically mention that, logically, a payment of zero euros was possible, because an anchor effect caused by this should be avoided. Participants in the group that received communication of a social background also were told that half of their purchase price would be donated to the research institute Kinderkrebs-Zentrum Hamburg gGmbH. Finally, there was an open question that queried the participant's WTP. To ensure valid results, the participants were pleased to indicate an exact amount of money and to not round off to whole numbers. The pretest showed that this request had the desired effect. The following page listed questions concerning the participant's understanding and perception of the PWYW situation to allow later evaluation of the usability of the data for analysis and to ensure valid outcomes. Moreover, the questionnaire included some qualitative, explorative questions to create interesting content about customers' motives and attitudes about PWYW. Subsequently, altruism was measured using the 7-point Likert-type scale. Four other thematically related attributes also were surveyed with the 7-point Likerttype scale to deflect from the purpose of measuring altruism. For all the attributes, established and empirically proven scales were used and the total of 19 items was presented in random order. As already described, altruism was assessed based on the scale from the International Personality Item Pool [32]. Kim et al. also made use of this scale in their first investigation of PWYW [4]. An adequate translation of the items from English to German was provided from Gahler [6]. Moreover, this set of questions contained a control item to identify participants who were not serious in completing their questionnaire and for e.g. selected for every item the same level on the scale just to finish the survey as quick as possible and get a certificate of participation afterward. After the capture of online purchase frequency and, if applicable, internal reference price, questions about sociodemographic details followed to ascertain sample composition and allow us to draw conclusions about participants' response patterns. The questionnaires ended by thanking the participants for their time and providing space for questions, comments and the option to state one's matriculation number for those students of the Leuphana University Lueneburg who needed a certificate for their participation in the survey.

\subsection{Analysis of Data and Altruism Scale}

The analyzed data did not contain any outliers related to altruism or WTP. This 
is quite comprehensible because of the freedom of pricing that comes with PWYW and the present result of a price range of zero to 30 euros. Prices greater than 16.90 euros only occurred in the group that had received communication of a social background for the purchase. Moreover, the minimum of zero euros was chosen by only 4 of 403 participants. Because of the predetermined value range and the use of a 7-point Likert-type scale, no outliers were possible for altruism. Although there was no need for a factor analysis because we used an established scale from the International Personality Item Pool, a reliability analysis was conducted to examine the scale's suitability for the specific, present sample (see Table 1(a) and Table 1(b)). This analysis confirmed the internal consistency of the scale with a Cronbach's alpha of 0.780 . Moreover, this value could not been improved by eliminating one of the five items. All of the items showed sufficient discriminatory power $(\geq 0.30)$. The two subgroups of the two factor levels of the independent variable social background turned out to be so similar in the measured sociodemographic aspects that differences in WTP could not be traced back to these factors. Furthermore, the groups were comparable in size: 204 participants (Group 1) got no information about social background and 199 participants (Group 2) received the information about donation. Any differences in WTP could be plausibly explained by variations in the variable social background.

\section{Results}

The distribution of the dependent variable willingness to pay seemed to differ in the two groups (Figure 1). With the help of a $t$-test for two independent samples, we tested the significance of this difference. Only the requirement of homogeneous variances was not met as a Levene's test revealed, so that a Welch's test was conducted; this is a $t$-test modified for groups with inhomogeneous variances (Table 2). The calculations showed a significance level of 5\%, a highly significant difference $(t(344.241)=-10.814, p<0.001)$ : WTP in group 2 with communication of a social background $(M=14.75, S D=5.55)$ is greater than

Table 1. Reliability analysis of the altruism scale from the international personality item pool.

(a)

\begin{tabular}{ccc}
\hline \multicolumn{2}{c}{ Cronbach's Alpha } & \multicolumn{2}{c}{ Number of Items } \\
\hline 0.780 & $(\mathrm{~b})$ & \\
\hline & Corrected Item-Total Correlation & Cronbach's Alphaif \\
& (Discriminatory Power) & Item Deleted \\
\hline I love to help others & 0.537 & 0.747 \\
I am concerned about others & 0.610 & 0.720 \\
I make people feel welcome & 0.694 & 0.696 \\
I anticipate the needs of others & 0.442 & 0.779 \\
I have a good word for everyone & 0.521 & 0.751 \\
\hline
\end{tabular}

Note: The items have been translated from German. 
WTP in group 1 without communication of a social background $(M=9.76, S D=$ 3.51). Table 2 also reports that the $95 \%$ confidence interval of the difference does not include the value zero. This also speaks for the existence of the difference. Comparing the distribution of altruism in group $1(M=5.49, S D=0.80)$ and group $2(M=5.45, S D=0.82)$, a $t$-test for two independent samples with a prior Levene's test confirms homoscedasticity $(f(1,401)=0.037, p=0.847)$ and that

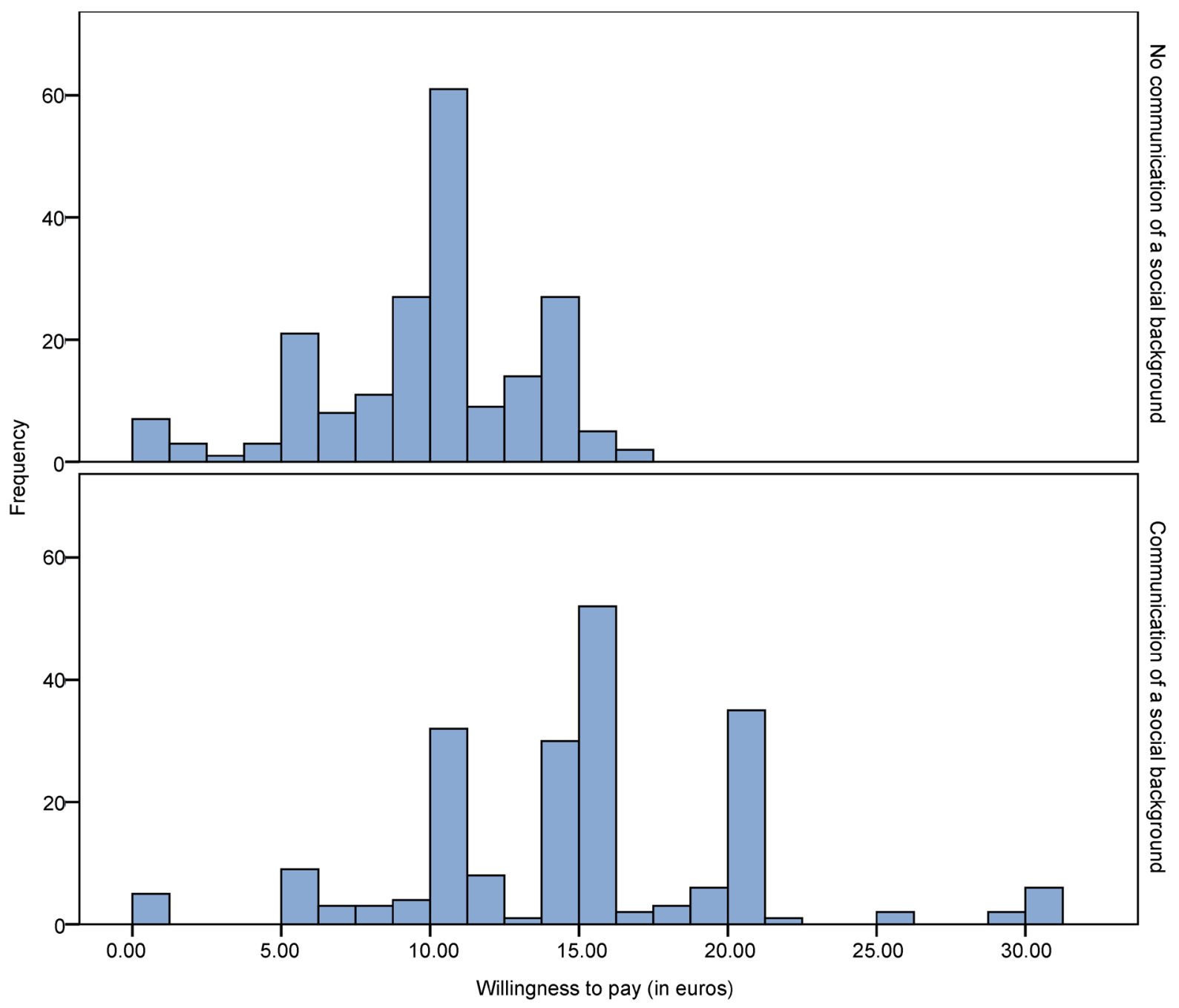

Figure 1. Histograms indicate that WTP value distribution is dependent on communication of a social background. Bars reflect for each group how often the participants stated which willingness to pay.

Table 2. $t$-test for the significance of the difference between the means of the willingness to pay of two independent samples.

\begin{tabular}{|c|c|c|c|c|c|c|c|c|c|}
\hline & \multicolumn{2}{|c|}{$\begin{array}{l}\text { Levene's Test for } \\
\text { Equality of Variances }\end{array}$} & \multicolumn{7}{|c|}{$t$-test for Equality of Means } \\
\hline & \multirow[t]{2}{*}{$F$} & \multirow[t]{2}{*}{ Sig. } & \multirow[t]{2}{*}{$T$} & \multirow[t]{2}{*}{$d f$} & \multirow{2}{*}{$\begin{array}{c}\text { Sig. } \\
\text { (2-Tailed) }\end{array}$} & \multirow{2}{*}{$\begin{array}{c}\text { Mean } \\
\text { Difference }\end{array}$} & \multirow{2}{*}{$\begin{array}{c}\text { Standard } \\
\text { Error Difference }\end{array}$} & \multicolumn{2}{|c|}{$\begin{array}{l}\text { 95\% Confidence Interval } \\
\text { of the Difference }\end{array}$} \\
\hline & & & & & & & & Lower & Upper \\
\hline Equal Variances Assumed & 18.311 & 0.000 & -10.757 & 401 & 0.000 & -4.98976 & 0.46386 & -5.90167 & -4.07785 \\
\hline Equal Variances Not Assumed & & & -10.814 & 344.241 & 0.000 & -4.98976 & 0.46140 & -5.89727 & -4.08225 \\
\hline
\end{tabular}

Note: The bottom row displays the results of the Welch's $t$-test. 
the means do not differ significantly $(t(401)=0.477, p=0.633)$. This ensures that altruism cannot be responsible for the unequal WTP of the two groups.

The hypothesized positive impact of altruism on WTP was tested using a separate simple linear regression analysis $(\mathrm{alpha}=5 \%)$ in each group. Figure 2 displays the assumed linear relations with the tested regression coefficients. After successfully checking that all requirements were met, we found that in group 1, the regression coefficient does not differ significantly from zero $(t=-1.083, p=$ 0.280 ). This is contradicted by the results for group 2: Because of the statistical calculations, the tested positive regression coefficient of altruism was significant $(t=4.602, p<0.001)$. Consequently, there exists a positive correlation between altruism and WTP only on condition that social background is communicated.

\section{Conclusions}

The experiment and data analyses we conducted allow unprecedented conclusions about the influence of altruism and social background on WTP in an anonymous PWYW purchase situation on the Internet. We hypothesized that both factors would exhibit positive impacts on WTP. The hypothesis that social background influenced WTP positively was confirmed because participants who received the information that half of their purchase price would be donated to the research institute of the Kinderkrebs-Zentrum Hamburg gGmbH chose on average a significantly higher price than participants who did not receive this information. In contrast, the hypothesis concerning the impact of altruism cannot be fully accepted because this effect only shows up in the group of participants to whom the social background is communicated. In the other group, there was no correlation between altruism and WTP. We therefore, conclude that for the present study, an interaction effect exists in addition to the main effect of the independent variable social background: Altruism only positively influenced WTP if the participant received information that half of the purchase price would be donated. The variable social background thus functions as a moderator variable in the correlation between altruism and WTP.

Interpretation of the results requires critical reflection on some aspects of the study. This has to be kept in mind although these aspects mainly represent limits that generally occur in the conduct of the given type of experiment and in the course of student degree theses. The validity of the results is limited in the fact that it cannot be assumed WTP would be on the same level in examinations of real practice or the whole population. However, this study concentrates less on the price itself and more on whether WTP changes with the communication of a social background and correlates with altruism and thus on relative proportionalities. For findings concerning this matter, generalizability to the German population can definitely be assumed. Because we conducted an online study, it was not possible to control whether each participant completed the survey only once, provided correct information and was not influenced by external confounding variables. However, we can assume that the questionnaires were completed conscientiously because of the study's short duration and simplicity and 


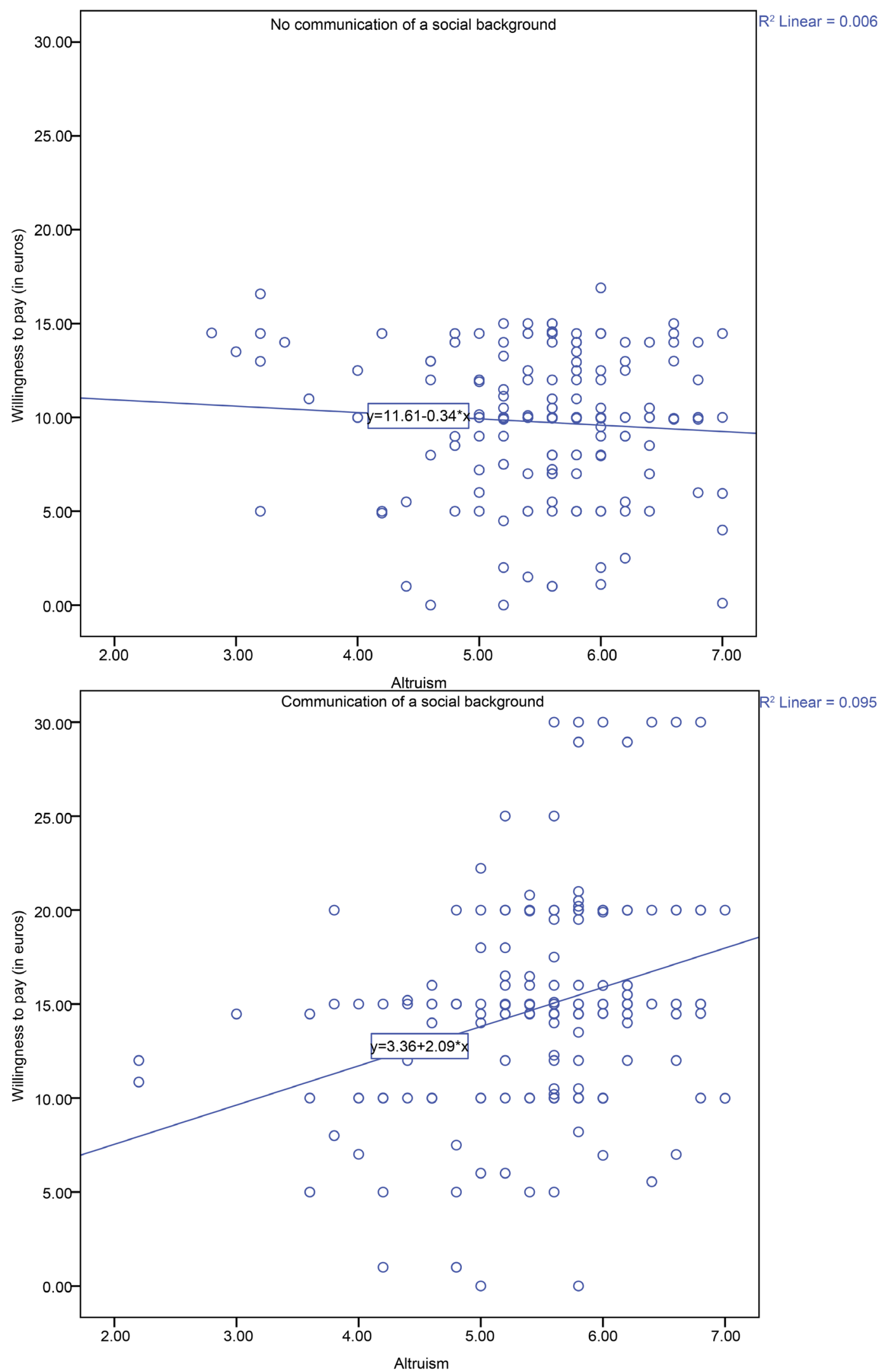

Figure 2. Scatter plots modeling the detected effects. Note: The regression coefficient of the graph of the group without communication of a social background was not significant. Altruism and WTP were solely significantly correlated when a social background was communicated. 
the participants', especially students', knowledge of the importance of such experiments. Furthermore, the PWYW situation has only been simulated and Marett, Pearson and Moore [38] have indicated that stated WTP is greater than what people would really pay. Therefore, statements that are derived from the determined WTP should be treated with caution. Moreover, all of the data were acquired from self-evaluation, which might lead to bias because of participants with (deliberately) false self-assessments. With appeals to the conscience of the participants and by ensuring that no identification of them would be possible, this issue was relativized. One must also consider that the obtained WTP might depend upon the selection of a non digital guidebook as specific product and the decision to mention a specific charitable institution. Finally, the results might not be fully transferable to the general population because of the sample characteristics, which were relatively homogenous in terms of the youth of the participants, level of education and income and the participation of females. Therefore, when comparing the findings with samples of other studies or customer bases of practical PWYW applications, one must take into account that WTP for the German population might be greater than that for this experiment's sample. The transferability of effects of the sample involved no such problems. In support of this contention, Gahler rejected his hypothesis that the positive impact of altruism on WTP was stronger for women than for men [6]. Moreover, there are no ethical concerns within the study conducted.

The findings on the impact of social background on WTP replicate the little previous findings and provide much needed evidence for related theoretical assumptions. The findings of Gneezy et al. [30] can be widened by the fact that the positive influence of a social background also influences anonymous purchase scenarios. Thus, the combination of PWYW and social background becomes an alternative pricing concept that leads to higher prices set by the customers than pure PWYW. Previous research on the impact of altruism on WTP in the online world found either no or only a weak positive influence [4] [6] [7]. The result of this study indicates that altruism is not meaningless when one applies PWYW on the anonymous Internet but that more altruistic people only pay more than less altruistic people when they have another incentive for a good deed. Solely having the chance to do the seller, good by paying a relatively high price does not seem to be sufficient. The provision of information about donation is the trigger for more altruistic people paying more than less altruistic people. In a further step, this can be interpreted to suggest that the social motif altruism affects not the seller but the donation or the recipient. This realization may explain why it has often been postulated but rarely proved that altruism positively impacts WTP. Although early research concluded that anonymity impacted the influence of altruism [4], later research rejected this thesis [6] [7] [15] [19]. The newly detected interaction effect confirms this insofar as altruism needs additional conditions to influence WTP on the Internet but that these conditions do not include the absence of anonymity.

Assessment of the application of PWYW also must consider how WTP acts in 
proportion to regular fixed prices. In the present study, the participants received the information about an external reference price of 14.47 euros. In the group that received no communication about a social background, the average WTP was 9.76 euros, which was clearly lower than the regular fixed price. In the group that received communication about a social background, the average WTP was 14.75 euros, but subtraction of the $50 \%$ to be donated, the seller ended up with less than from the group without the charity background. However, the result might be different when examining another customer base, another product or service or a different external reference price. Furthermore, PWYW does not imply that the seller's goal is to increase the profit per product sold. Based on this study's findings, PWYW is recommended when the seller wants to apply it solely temporarily to gain attention and wants the buyers to pay something but not necessarily as much or even more than the regular fixed price. Thereby, the seller can stand out from his competitors by making use of this innovative, partially unknown pricing mechanism. By adding a fundraising campaign, sellers might not earn more money than when applying pure PWYW but might improve customer reputation.

Regarding profit, factors such as the cost structure of the product or service also play a role. With high fixed but low variable costs, PWYW can drive profit by considerably increasing the number of customers even when these pay less than the regular fixed price. The question of whether a social background influences the number of customers represents another area for further research. It is imaginable that designing such a sales concept may be attractive to customers and may convince people to buy the product or service from this specific seller. Nevertheless, it might also be that people disapprove of this concept because when donating something, they want to do this of their own accord and to a self-selected receiver. Buyers' behaviors depend largely on the specific characteristics of a PWYW situation, which makes it even more important for future research to try to replicate detected interdependencies and cause-effect relationships. This need is encouraged by the fact that the found interaction effect contrasts with studies which have found even if only weak main effect of altruism on WTP on the Internet [6] [7] [19]. As long as sellers determine what percentage of the price will be donated, they can remain indifferent about whether the customer's altruism affects the sale or the donation.

Subsequent research might test whether the correlation between altruism and WTP in the online world can be moderated by variables other than social background that might offer a chance for a good deed or appeal to customers' altruism. Furthermore, it seems interesting to examine whether the detected effects are attributable to the specifically designed characteristics of the simulated scenario, such as the provision of an external reference price, the choice of a rather low priced, non digital product and the choice of the research institute of the Kinderkrebs-Zentrum Hamburg gGmbH as recipient. Roy et al. [17] found that in the absence of an external reference price, buyers' internal reference prices acted as a mediator variable in the positive influence of altruism on WTP. An 
American study revealed that the willingness to donate was higher when people knew that their money went directly to the specific project and would not be used to cover costs of the institution such as employee compensation [39]. In addition, the researchers noted that this could be traced back to warm-glow altruism: Donors perceived a greater sense of well-being with this knowledge. It consequently can be hypothesized that the choice of a regionally located charitable recipient instead of an international institution impacts the existence and strength of the social background's influence on WTP. With a more specific and more closely located organization, it becomes easier to retrace for what the donations are used and whether the institution makes progress. Moreover, it does not seem to be far-fetched that conducting the same experiment using a sample with a higher income level but the same distribution of altruism would let sellers increase their profit more when applying PWYW in combination with a social background than when applying pure PWYW. To gain this result, higher income levels would be necessary to ensure a greater WTP and that both effects are much more pronounced with buyers with higher income levels.

Finally, the present study represents an innovative research on PWYW and succeeds in producing new knowledge about the impact on altruism and social background on WTP. Especially the interaction effect of these two factors on WTP has not even been taken into consideration before and when was detected for the first time. This investigation does not only reduce research gaps but also serve to explain further problems in proving a positive influence of altruism on WTP. Moreover, they are helpful for practical applications of PWYW.

PWYW means sellers do not have direct control over prices. However, the results of this study show that the use of PWYW does not take the whole power in the purchase situation away from the seller: By shaping a PWYW scenario intelligently, sellers can seemingly influence what the customer's WTP orientates on and can set stimuli that might positively affect WTP.

\section{References}

[1] Simon, H. and Fassnacht, M. (2016) Preismanagement: Strategie-Analyse-Entscheidung-Umsetzung. 4th Edition, Springer Gabler, Wiesbaden. https://doi.org/10.1007/978-3-658-11871-6

[2] Kim, J.-Y. (2008) Das Projekt: Pay-What-You-Want. http://www.pay-what-you-want.net

[3] Schößler, T. (2016) Preispolitik für Theater: Strategische Preisgestaltung zwischen Einnahmesteigerung und öffentlichem Auftrag. Springer VS, Wiesbaden.

https://doi.org/10.1007/978-3-658-14613-9

[4] Kim, J.-Y., Natter, M. and Spann, M. (2009) Pay What You Want: A New Participative Pricing Mechanism. Journal of Marketing, 73, 44-58.

https://doi.org/10.1509/jmkg.73.1.44

[5] Rossel, L. (2014) Vergütungsmodell Pay What You Want: Wenn Kunden den Preis für ein Gut bestimmen.

http://www.wiwo.de/erfolg/trends/verguetungsmodell-pay-what-you-want-wenn-k unden-den-preis-fuer-ein-gut-bestimmen/10709678

[6] Gahler, M. (2016) Pay-What-You-Want im Internet: Empirische Analyse der Ein- 
flussgrößen auf die freiwillige Zahlungsbereitschaft. Springer Gabler, Wiesbaden. https://doi.org/10.1007/978-3-658-12201-0

[7] Regner, T. (2010) Why Consumers Pay Voluntarily: Evidence from Online Music. Jena Economic Research Papers, 081. http://hdl.handle.net/10419/56912

[8] Hinz, O. (2008) Interaktive Preismechanismen in dynamischen Märkten. Verlag DR. KOVAC, Hamburg.

[9] Chandran, S. and Morwitz, V.G. (2005) Effects of Participative Pricing on Consumers' Cognitions and Actions: A Goal Theoretic Perspective. Journal of Consumer Research, 32, 249-259. https://doi.org/10.1086/432234

[10] Der Wiener Deewan (2015). http://www.stadtbekannt.at/der-wiener-deewan/

[11] Kunter, M. (2015) Exploring the Pay-What-You-Want Payment Motivation. Journal of Business Research, 68, 2347-2357.

[12] Kim, J.-Y., Natter, M. and Spann, M. (2010) Pay-What-You-Want-Praxisrelevanz und Konsumentenverhalten. Zeitschrift für Betriebswirtschaft, 80, 147-169. http://www.ecm.bwl.uni-muenchen.de/publikationen/pdf/pwyw-zfb.pdf https://doi.org/10.1007/s11573-009-0345-7

[13] Riener, G. and Traxler, C. (2012) Norms, Moods, and Free Lunch: Longitudinal Evidence on Payments from a Pay-What-You-Want Restaurant. The Journal of Socio-Economics, 41, 476-483.

[14] Gneezy, A., Gneezy, U., Riener, G. and Nelson, L. (2012) Pay-What-You-Want, Identity, and Self-Signaling in Markets. Proceedings of the National Academy of Sciences of the United States of America, 109, 7236-7240.

https://doi.org/10.1073/pnas.1120893109

[15] Schmidt, K., Spann, M. and Zeithammer, R. (2015) Pay What You Want as a Marketing Strategy in Monopolistic and Competitive Markets. Management Science, 61, 1217-1236. https://doi.org/10.1287/mnsc.2014.1946

[16] Schons, L.M., Rese, M., Wieseke, J., Rasmussen, W., Weber, D. and Strotmann, W.C. (2014) There Is Nothing Permanent Except Change-Analyzing Individual Price Dynamics in "Pay-What-You-Want" Situations. Marketing Letters, 25, 25-36. https://doi.org/10.1007/s11002-013-9237-2

[17] Roy, R., Rabbanee, F.K. and Sharma, P. (2015) Antecedents, Outcomes, and Mediating Role of Internal Reference Prices in Pay-What-You-Want (PWYW) Pricing. Marketing Intelligence \& Planning, 34, 117-136. https://doi.org/10.1108/MIP-08-2015-0157

[18] Hilbert, L.P. and Suessmair, A. (2015) The Effects of Social Interaction and Social Norm Compliance in Pay-What-You-Want Situations. American Journal of Industrial and Business Management, 5, 548-556.

https://doi.org/10.4236/ajibm.2015.58054

[19] Dorn, T. and Suessmair, A. (2016) Is It Really Worth It? A Test of Pay-What-YouWant Pricing Strategies in a German Consumer Behaviour Context. Global Business and Economics Review, 18, 82-100. https://doi.org/10.1504/GBER.2016.073321

[20] Lee, S.R., Baumgartner, H. and Pieters, R. (2011) Are You Really Paying What You Wish?: Interpersonal Influences on Price Decisions. In: Ahluwalia, R., Chartrand, T.L. and Ratner, R.K., Eds., NA-Advances in Consumer Research, Vol. 39, Association for Consumer Research, Duluth, MN, 540-541. http://www.acrwebsite.org/volumes/v39/acr_v39_9708.pdf

[21] Regner, T. and Riener, G. (2012) Voluntary Payments, Privacy and Social Pressure on the Internet: A Natural Field Experiment. DICE Discussion Paper, 82. http://www.dice.hhu.de/fileadmin/redaktion/Fakultaeten/Wirtschaftswissenschaftli 
che_Fakultaet/DICE/Discussion_Paper/082_Regner_Riener.pdf

[22] Armstrong Soule, C. and Madrigal, R. (2015) Anchors and Norms in Anonymous Pay-What-You-Want Pricing Contexts. Journal of Behavioral and Experimental Economics, 57, 167-175.

[23] Jang, H. and Chu, W. (2012) Are Consumers Acting Fairy Toward Companies? An Examination of Pay-What-You-Want-Pricing. Journal of Macromarketing, 32, 348 360. https://doi.org/10.1177/0276146712448193

[24] Johnson, J.W. and Cui, A.P. (2013) To Influence or Not to Influence: External Reference Price Strategies in Pay-What-You-Want Pricing. Journal of Business Research, 66, 275-281.

[25] Kim, J.-Y., Kaufmann, K. and Stegemann, M. (2014) The Impact of Buyer-Seller Relationships and Reference Prices on the Effectiveness of the Pay What You Want Pricing Mechanism. Marketing Letters, 25, 409-423. https://doi.org/10.1007/s11002-013-9261-2

[26] Thomas, S. and Gierl, H. (2014) Pay What You Want: How to Affect the Price Consumers Are Willing to Pay. Proceedings of the 13th ICORIA: International Conference on Research in Advertising, Amsterdam, 26-28 June 2014.

[27] Singer, T. and Ricard, M. (2015) Mitgefühl in der Wirtschaft: Ein bahnbrechender Forschungsbericht. Albrecht Knaus Verlag, München.

[28] Jung, M., Nelson, L., Gneezy, A. and Gneezy, U. (2014) Paying More When Paying for Others. Journal of Personality and Social Psychology, 107, 414-431.

https://doi.org/10.1037/a0037345

[29] Shelle, S. and Morwitz, V. (2013) We're in This Together: How Sellers, Social Values, and Relationship Norms Influence Consumer Payments in Pay-What-YouWant Contexts. Unpublished.

http://www8.gsb.columbia.edu/programs/sites/programs/files/marketing/seminar_p apers/paper_santana_fa13.pdf

[30] Gneezy, A., Gneezy, U., Nelson, L. and Brown, A. (2010) Shared Social Responsibility: A Field Experiment in Pay-What-You-Want Pricing and Charitable Giving. Science, 329, 325-326. https://doi.org/10.1126/science.1186744

[31] Huber, O. (2013) Das psychologische Experiment: Eine Einführung. Verlag Hans Huber, Bern.

[32] Goldberg, L. (2014) 30 NEO Facets: Altruism. http://ipip.ori.org/newNEOKey.htm\#Altruism

[33] BITKOM (2013) Trends im E-Commerce: Konsumverhalten beim Online-Shopping. Bundesverband Informationswirtschaft, Telekommunikation und neue $\mathrm{Me}$ dien e.V., Hrsg. https://www.bitkom.org/Bitkom/Publikationen/Trends-im-E-Commerce.html

[34] Brandt, M. (2015) Das kaufen deutsche Onlineshopper. https://de.statista.com/infografik/3421/waren-dienstleistungen-die-deutsche-online -kaufen

[35] Meyer, R. (2003) E-Commerce: Grundlagen und Praxiswissen für den Online-Handel. Verlag Dr. Müller e.K. und Lizenzgeber, Düsseldorf.

[36] Börsenverein des Deutschen Buchhandels (2016) Durchschnittspreis von Reiseführern in Deutschland bis 2015. Börsenblatt, 12, 30.

https://de.statista.com/statistik/daten/studie/292467/umfrage/durchschnittspreis-vo n-reisefuehrern-in-deutschland

[37] Small, D. and Loewenstein, G. (2003) Helping a Victim or Helping the Victim: Altruism and Identifiability. The Journal of Risk and Uncertainty, 26, 5-16. 
https://doi.org/10.1023/A:1022299422219

[38] Marett, K., Pearson, R. and Moore, R. (2012) Pay What You Want: An Exploratory Study of Social Exchange and Buyer-Determined Prices of iProducts. Communications of the Association for Information Systems, 30, Article 10.

[39] Gneezy, U., Keenan, E. and Gneezy, A. (2014) Avoiding Overhead Aversion in Charity. Science, 346, 632-635. https://doi.org/10.1126/science.1253932 


\section{Appendix}

1) Adapted print version of the used online questionnaire for the group without communication of a social background ("Group 1")

Note: The questionnaire has been translated from German.

[Page 1: General information on the survey]

Dear participant, thank you for participating in my study. Therewith you make a valuable contribution to support my bachelor thesis.

First, please carefully read some hints:

The following questionnaire will take 5 to 10 minutes. I request you to behave as conscientiously as possible in filling out the questionnaire.

As I am interested in your personal attitudes and opinions, there are no "right" or "wrong" answers.

Your data will of course be treated absolutely confidentially and will be evaluated anonymously. The data collected will be used exclusively for scientific research purposes.

If there are any queries or technical problems, feel free to contact me.

Email: hanna.peschla@stud.leuphana.de

Now please click on "Next".

[Page 2: Please put yourself notionally in the following situation]:

On the occasion of an imminent vacation you want to order a guidebook via the Internet. After ordering, you pay by bank transfer. The book will be sent to you subsequently.

At a trusted provider you discover the guidebook of your choice. The book usually costs $14.47 €$ but the seller is currently using a new concept: You as the buyer decide how much you pay. The seller accepts every offer.

In sum: You pay as much for the book as you want to.

Your name and purchase price will not be published on the sales platform or elsewhere at any time.

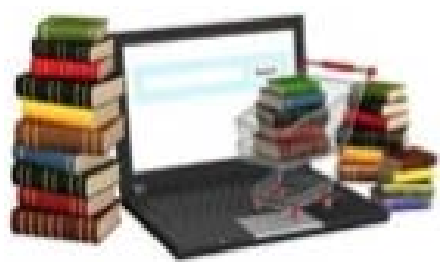

You decide to order the book from this seller. How much are you willing to pay for it?

Please indicate an exact amount of euros down to the last cent and do not round off to whole numbers.

$\square \square$ euros, $\square \square$ cents

[Page 3: Questionnaire]

When selecting your purchase price, were you aware that you could also indicate an amount of $0.00 €$ ?

$\square$ Yes $\square$ No 
If no: In your opinion, what was the lowest amount of money you could have indicated?

$\square \square$ euros, $\square \square$ cents

Would you consider the price you have indicated as fair? $\square$ Yes $\quad \square$ No

Please substantiate your valuation of fairness briefly:

Do you think that other customers tend to rather pay a higher, lower or an equal amount of money?

$\square$ Higher $\square$ Lower $\square$ Equal

\section{[Page 4: Continuation of the questionnaire]}

Please edit the following statements and questions by means of the given response options.

Again, there are no "right" or "wrong" answers but it is about your personal assessment.

At first, please carefully take a look at the scale inscription. Always chose the level about which you think that it applies to you best.

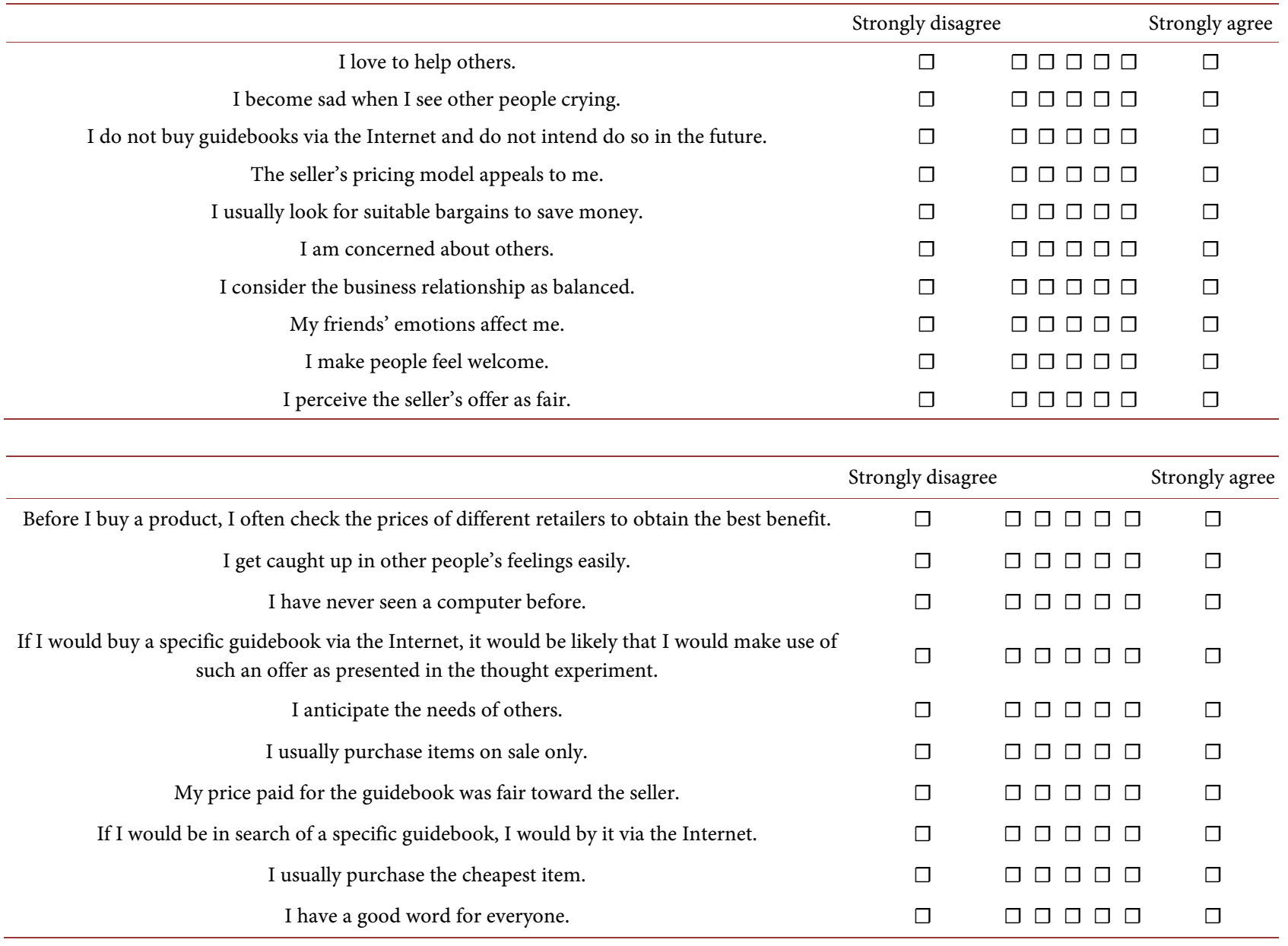

\section{[Page 5: Continuation of the questionnaire]}

How often do you buy items via the Internet?

$\square$ Daily $\quad \square$ Several times a week $\square$ About once a week 
Several times a month Rarely

Never

Have you ever ordered a guidebook via the Internet before? $\square$ Yes No

If yes: Please remember the last time you ordered a guidebook via the Internet. How much did you pay for it?

$\square \square$ euros, $\square \square$ cents

[Page 6: Sociodemografic details]

Finally, please provide some sociodemografic details about your person. They serve to recognize the sample composition.

Gender: $\quad \square$ Female $\quad \square$ Male

Age: $\quad \square \square$ years

Nationality (For e.g. German):

Highest level of education attained:

$\square$ No educational achievement $\square$ Lower secondary school certificate ("Hauptschulabschluss")

$\square$ Secondary school certificate ("Realschulabschluss")

$\square$ (Subject-linked) Higher education entrance qualification

$\square$ University degree $\square$ Doctorate $\square$ Other educational achievement

Professional career:

$\begin{array}{lll}\square \text { Pupil } & \square \text { Civil service } & \square \text { Apprentice } \\ \square \text { Student } & \square \text { Employee } & \square \text { Official } \\ \square \text { Self-employed person } & \square \text { Unemployed } & \square \text { Housewife/-husband } \\ \square \text { Pensioner } & \square \text { Any other activity } & \square \text { Not specified }\end{array}$

Monthly net income:

$\square$ Under $1000 € \square 1001-2000 € \quad \square 2001-3000 € \quad \square$ Over $3000 € \square$

Not specified

[Page 7: End of the study]

Thank you for your participation in my study.

If there are any questions, comments or the like left, please indicate them here:

If you are a student of the Leuphana University Lueneburg and need a certificate for your participation in the survey, please indicate your matriculation number here:

The pieces of paper for the certificate of participation can be handed in at the secretary's office of the campus "Rotes Feld". Mrs. Tienken is responsible for the signatures.

2) Adapted print version of the used online questionnaire for the group with communication of a social background ("Group 2")

Note: The questionnaire has been translated from German.

[Page 1: General information on the survey]

Dear participant, thank you for participating in my study. Therewith you make a valuable contribution to support my bachelor thesis.

First, please carefully read some hints:

The following questionnaire will take 5 to 10 minutes. I request you to behave 
as conscientiously as possible in filling out the questionnaire.

As I am interested in your personal attitudes and opinions, there are no "right" or "wrong" answers.

Your data will of course be treated absolutely confidentially and will be evaluated anonymously. The data collected will be used exclusively for scientific research purposes.

If there are any queries or technical problems, feel free to contact me.

Email: hanna.peschla@stud.leuphana.de

Now please click on "Next".

[Page 2: Please put yourself notionally in the following situation]:

On the occasion of an imminent vacation you want to order a guidebook via the Internet. After ordering, you pay by bank transfer. The book will be sent to you subsequently.

At a trusted provider you discover the guidebook of your choice. The book usually costs $14.47 €$ but the seller is currently using a new concept: You as the buyer decide how much you pay. The seller accepts every offer.

In the course of this sales campaign, the seller additionally donates exactly half of each respectively selected purchase price to the research institute of the Kinderkrebs-Zentrum Hamburg gGmbH. This Hamburg-based institute is doing research on new methods for diagnosis and treatment of childhood cancer.

In sum: You pay as much for the book as you want to. Half of your selected purchase price will be donated to the research institute of the Kinderkrebs-Zentrum Hamburg gGmbH.

Your name and purchase price will not be published on the sales platform or elsewhere at any time.
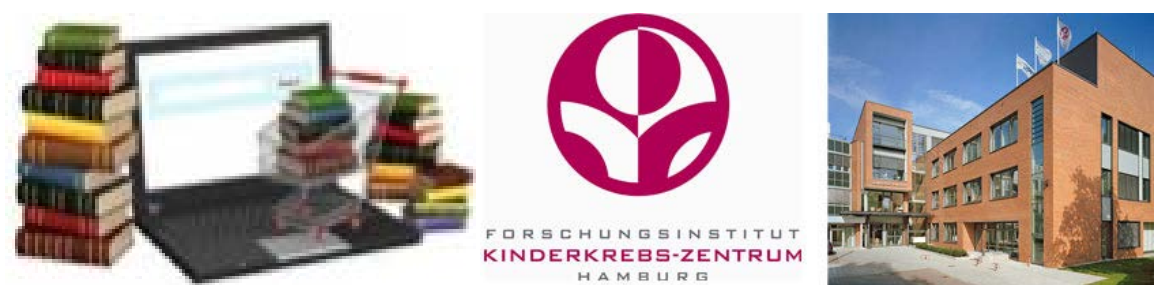

You decide to order the book from this seller. How much are you willing to pay for it?

Please indicate an exact amount of euros down to the last cent and do not round off to whole numbers.

$\square \square$ euros, $\square \square$ cents

\section{[Page 3: Questionnaire]}

When selecting your purchase price, were you aware that you could also indicate an amount of $0.00 €$ ?

$\square$ Yes $\quad \square$ No

If no: In your opinion, what was the lowest amount of money you could have indicated?

$\square \square$ euros, $\square \square$ cents 
Would you consider the price you have indicated as fair? $\square$ Yes $\square$ No

Please substantiate your valuation of fairness briefly:

Do you think that other customers tend to rather pay a higher, lower or an equal amount of money?

$\square$ Higher $\square$ Lower $\square$ Equal

At the moment of your decision for an amount of money, did you have any doubts that half of your purchase price will be donated to the research institute of the Kinderkrebs-Zentrum Hamburg gGmbH?

$\square$ Yes $\quad \square$ No

[Page 4: Continuation of the questionnaire]

Please edit the following statements and questions by means of the given response options.

Again, there are no "right" or "wrong" answers but it is about your personal assessment.

At first, please carefully take a look at the scale inscription. Always chose the level about which you think that it applies to you best.

\begin{tabular}{|c|c|c|c|}
\hline & Strongly disagree & & Strongly agree \\
\hline I love to help others. & $\square$ & वロロロ & $\square$ \\
\hline I become sad when I see other people crying. & $\square$ & 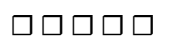 & $\square$ \\
\hline I do not buy guidebooks via the Internet and do not intend do so in the future. & $\square$ & ロロロロ & $\square$ \\
\hline The seller's pricing model appeals to me. & $\square$ & ロロロロ & $\square$ \\
\hline I usually look for suitable bargains to save money. & $\square$ & $\square \square \square \square \square$ & $\square$ \\
\hline I am concerned about others. & $\square$ & $\square \square \square \square \square$ & $\square$ \\
\hline I consider the business relationship as balanced. & $\square$ & $\square \square \square \square \square$ & $\square$ \\
\hline My friends' emotions affect me. & $\square$ & 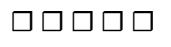 & $\square$ \\
\hline I make people feel welcome. & $\square$ & $\square \square \square \square \square$ & $\square$ \\
\hline I perceive the seller's offer as fair. & $\square$ & ロロロロ & $\square$ \\
\hline & Strongly disagree & & Strongly agree \\
\hline Before I buy a product, I often check the prices of different retailers to obtain the best benefit. & $\square$ & वロ०ロ & $\square$ \\
\hline I get caught up in other people's feelings easily. & $\square$ & ㅁㅁ & $\square$ \\
\hline I have never seen a computer before. & $\square$ & $\square \square \square \square \square$ & $\square$ \\
\hline $\begin{array}{l}\text { If I would buy a specific guidebook via the Internet, it would be likely that I would make use of } \\
\text { such an offer as presented in the thought experiment. }\end{array}$ & $\square$ & $\square \square \square \square \square$ & $\square$ \\
\hline I anticipate the needs of others. & $\square$ & $\square \square \square \square \square$ & $\square$ \\
\hline I usually purchase items on sale only. & $\square$ & $\square \square \square \square \square$ & $\square$ \\
\hline My price paid for the guidebook was fair toward the seller. & $\square$ & वロロロ & $\square$ \\
\hline If I would be in search of a specific guidebook, I would by it via the Internet. & $\square$ & $\square \square \square \square \square$ & $\square$ \\
\hline I usually purchase the cheapest item. & $\square$ & ロロロロ & $\square$ \\
\hline I have a good word for everyone. & $\square$ & $\square \square \square \square \square$ & $\square$ \\
\hline
\end{tabular}

\section{[Page 5: Continuation of the questionnaire]}

How often do you buy items via the Internet?

$\square$ Daily $\quad \square$ Several times a week $\square$ About once a week 
Several times a month $\square$ Rarely

$\square$ Never

Have you ever ordered a guidebook via the Internet before? $\square$ Yes

$\square$ No

If yes. Please remember the last time you ordered a guidebook via the Internet. How much did you pay for it?

$\square \square$ euros, $\square \square$ cents

\section{[Page 6: Sociodemografic details]}

Finally, please provide some sociodemografic details about your person. They serve to recognize the sample composition.

Gender: $\quad \square$ Female $\square$ Male

Age: $\quad \square \square$ years

Nationality (For e.g. German):

Highest level of education attained:

$\square$ No educational achievement $\square$ Lower secondary school certificate ("Hauptschulabschluss")

$\square$ Secondary school certificate ("Realschulabschluss")

$\square$ (Subject-linked) Higher education entrance qualification

$\square$ University degree $\square$ Doctorate $\square$ Other educational achievement

Professional career:

$\begin{array}{lll}\square \text { Pupil } & \square \text { Civil service } & \square \text { Apprentice } \\ \square \text { Student } & \square \text { Employee } & \square \text { Official } \\ \square \text { Self-employed person } & \square \text { Unemployed } & \square \text { Housewife/-husband } \\ \square \text { Pensioner } & \square \text { Any other activity } & \square \text { Not specified }\end{array}$

Monthly net income:

$\square$ Under $1000 € \square 1001-2000 € \quad \square 2001-3000 € \quad \square$ Over $3000 €$

Not specified

[Page 7: End of the study]

Thank you for your participation in my study.

If there are any questions, comments or the like left, please indicate them here:

If you are a student of the Leuphana University Lueneburg and need a certificate for your participation in the survey, please indicate your matriculation number here:

The pieces of paper for the certificate of participation can be handed in at the secretary's office of the campus "Rotes Feld". Mrs. Tienken is responsible for the signatures. 
Submit or recommend next manuscript to SCIRP and we will provide best service for you:

Accepting pre-submission inquiries through Email, Facebook, LinkedIn, Twitter, etc. A wide selection of journals (inclusive of 9 subjects, more than 200 journals)

Providing 24-hour high-quality service

User-friendly online submission system

Fair and swift peer-review system

Efficient typesetting and proofreading procedure

Display of the result of downloads and visits, as well as the number of cited articles Maximum dissemination of your research work

Submit your manuscript at: http://papersubmission.scirp.org/

Or contact ajibm@scirp.org 